\title{
Sex chromosome aberrations and speech development
}

\author{
MAUREEN GARVEY and DAVID E. MUTTON \\ From the Child Development Unit, Royal Manchester Children's Hospital, Pendlebury, and the Paediatric Research \\ Unit, Guy's Hospital Medical School, London
}

\begin{abstract}
Garvey, M., and Mutton, D. E. (1973). Archives of Disease in Childhood, 48, 937. Sex chromosome aberrations and speech development. When chromosome studies were made on 9 boys with grossly defective expressive speech but with normal levels of language comprehension, 3 were found to have abnormal karyotypes. 2 were mosaic (46,XY/47,XXY and 46,XY/47,XYY) and the third had 48 chromosomes with an XXYY sex chromosome complement. These results and data in published reports suggest that sex chromosome aneuploidy may play an important role in delaying and upsetting the development of higher neurological functions, for example those involved in communication and psychosocial adaptation and behaviour. The early diagnosis of such children and subsequent remedial and medical intervention may reduce the risk of psychiatric referral later in life.
\end{abstract}

Problems of communication in children due to lack of expressive speech have received little attention as a genetic problem. When these are associated with gross mental retardation, such as that caused by major chromosomal disorders, the origin is clear, many body systems being affected. However, the more common sex chromosome anomalies or the recognized variability of certain autosomal regions, while producing no gross somatic or neurological features, could be causative factors in minimal brain dysfunction, one expression of which might be retardation of speech development.

In published reports there is considerable evidence that sex chromosome anomalies are found more frequently in psychiatric populations. In addition, we have some evidence that such patients also show an increase in the frequency of chromosomal variants (Anders et al., 1968). These, together with clinical reports of variant chromosomes among children examined for speech assessment, suggested that a study for chromosome abnormality and variation among such children might be productive. It was decided, therefore, to conduct a pilot study to examine the chromosomes of a group of these children by regular microscopy and by the newer quinacrine fluorescence technique (Caspersson, Lomakka, and Zech, 1971). To exclude nonspecific mental impairment which might be responsible for the speech delay, patients were selected who had presented with gross retardation of

Received 12 June 1973. expressive speech, but with a normal comprehension of speech.

\section{Materials and methods}

Among approximately 450 children with severe speech and language problems, only 9 , aged 3 years or older, were found with language comprehension within at least the second SD below the mean, but with expressive speech $<-2 \mathrm{SD}$, both abilities being measured on the Reynell Developmental Language Scales (RDLS) (Reynell, 1969). For these children the levels of auditory perception and of verbal and manual expression were established through subtests of the Illinois Test of Psycholinguistics (ITPA) (Kirk, McCarthy, and Kirk, 1968). Lingual sensory motor abilities were measured on the Lingual Mobility Test (LMT) and the Magnitude Discrimination Test (MDT) (Fawcus, 1969). All children were examined for any major neuropsychological anomaly which might have affected response to these tests.

Blood collected in Manchester was mailed to the Paediatric Research Unit (PRU) in London for culture and analysis. Lymphocyte cultures were established using a microculture technique. Chromosome spreads for bright field analysis were stained with lacto-acetic orcein and for fluorescence analysis (Caspersson et al., 1971) with quinacrine mustard (Micro-Bio Laboratories Ltd.). At least 10 metaphase spreads were counted from each patient and if any aberration was found, further counts were made. Bright field and fluorescence karyotypes were prepared from each patient.

Analysis of chromosomal variants by bright field microscopy was made using the standards suggested by Lubs and Ruddle (1970a). For the fluorescent variants, comparison was made with a series of patients analysed at the PRU (D. E. Mutton, unpublished data). 
Comparison of language comprehension and exp $\overrightarrow{\mathbb{R}_{S}}$ ssi.

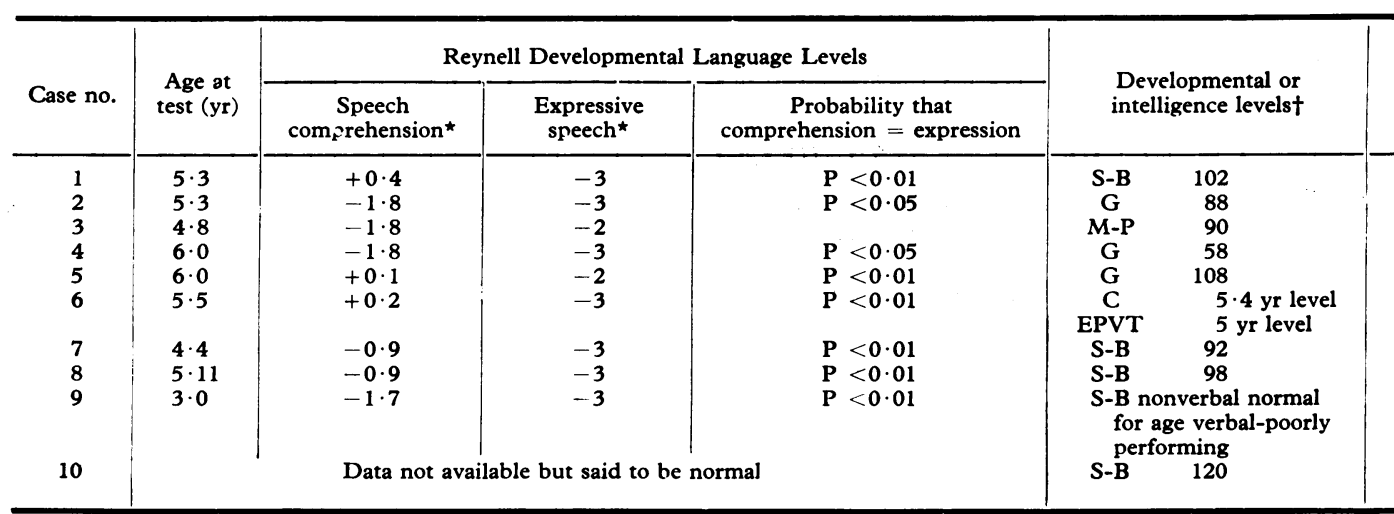

Note: Cases 1 and 10 are twins.

^Figures indicate number of SDs from normal mean.

tS-B, Stanford Binet Form I,-M; G, Griffiths Mental Developmental Scales; M-P, Merrill-Palmer; C, Columbia Mental Maturity Scale; EPV $¥$ A further 100 cells examined by fluorescence showed no $\mathrm{Y}$ negative metaphases, suggesting there is no $45, \mathrm{X}$ line in lymphocytes.

\section{Results}

Chromosome analysis showed no enlarged satellites or short arms of acrocentric chromosomes in any of the patients. Several carried chromosomes with intense variant bands but these were not unusual in size and their frequency was not greater than in the PRU sample. One patient (Case 2) had a moderately long Y-chromosome (equal in size to chromosome No. 18). This variation is present in about $0.3 \%$ of the general population (Lubs and Ruddle, 1970b), but may be purely a chance finding in such a small group. However, 3 patients showed a sex chromosome abnormality (Table I); one (Case 9) had XXYY sex chromosomes $(48, X X Y Y)$ while the other 2 (Cases 1 and 6) were mosaics, both with a high proportion of abnormal cells.

Case 1 has a twin sib (Case 10) with normal speech, and evidence from placentation and the distribution of fluorescent variants in the karyotypes of the twins support the view that they are monozygotic. Both were found to be mosaic 46,XY/ $47, \mathrm{XYY}$ on lymphocyte cultures, but whereas fibroblast cultures (Table II) showed only 47,XYY cells in the affected sib (a point supplemented by the high level of double Y-chromatin in oral smears), his twin is mosaic for normal, and abnormal lines in both fibroblasts and lymphocytes and oral smears show only a low proportion of double Y-chromatin. The origin of mosaicism in these twins is of interest in view of their probable monozygosity and yet their discordance on three counts, namely minor congenital anomalies in twin 1 (the reason for the 1967 cytogenetic study), their tissue cytology, and the speech defect. The simplest hypothetical explanation is that there was originally one $47, \mathrm{XYY}$ zygote in which separation of the blastomeres occurred to produce two monozygotic embryos. Subsequently, in one (Case 10) nondisjunction produced 46,XY/47,XYY mosaicism. With the development of placental anastamoses, the flow of blood between the fetuses produced marrow

\section{TABLE II}

Comparison of psycholinguistic and karyotypic findings in Case 1 and his 'normal' twin brother

\begin{tabular}{|c|c|c|}
\hline & Case 1 & Case 10 \\
\hline $\begin{array}{l}\text { ITPA Auditory Reception } \\
\text { Subtest } \\
\text { ITPA Verbal Expression } \\
\text { Subtest } \\
\text { ITPA Manual Expression } \\
\text { Subtest } \\
\text { Progressive coloured } \\
\text { matrices } \\
\text { Stanford-Binet L-M IQ } \\
\text { Fawcus MDT (5) correct } \\
\text { responses } \\
\text { Fawcus LMT (5) mean } \\
\text { time (sec) } \\
\text { Chromosome results } \\
\text { 1967^ } \\
\text { Skin fibroblasts } \\
\text { Lymphocytes } \\
\text { Diagnosis }\end{array}$ & $\begin{array}{c}35 \\
25 \\
34 \\
12 \\
102 \\
6 \\
60 \\
46 \quad 47 \\
0 \quad 300 \\
65 \text { 35 } \\
47, X Y Y \text { chimeric } \\
\text { for } 46, X Y \\
\text { lymphocytes }\end{array}$ & $\begin{array}{c}46 \\
28 \\
38 \\
12 \\
120 \\
6 \\
60 \\
46 \\
47 \\
40(\%) \\
55 \quad 45(\%) \\
\text { Mosaic } \\
46, X Y / 47, X Y Y\end{array}$ \\
\hline
\end{tabular}

ITPA, Illinois Test of Psycholinguistics; MDT, Magnitude Discrimination Test; LMT, Lingual Mobility Test.

${ }^{\star}$ Mr. L. Butler, Senior Cytogeneticist, Queen Elizabeth Hospital for Children, Hackney, London. 
gether with intelligence levels and chromosome results

\begin{tabular}{|c|c|c|c|c|c|c|c|c|}
\hline \multicolumn{6}{|c|}{ Chromosome counts } & \multirow{2}{*}{ Sex chromatin } & \multirow{2}{*}{ Comments } & \multirow{2}{*}{ Fluorescent variants } \\
\hline$<45$ & 45 & 46 & 47 & 48 & 49 & & & \\
\hline 3 & $\begin{array}{l}? 1 \\
4\end{array}$ & $\begin{array}{l}14 \\
10 \\
11 \\
12 \\
18\end{array}$ & 12 & $? 1$ & $\ddagger$ & Oral smears Y3 YY 25 & $\begin{array}{l}n=45 \text { random loss } \\
\text { Long } Y=18 \text { in length } \\
\text { Pronounced heterochromatic regions of } 1 \& 9\end{array}$ & $\begin{array}{c}14 s \\
3^{3} 13 p\end{array}$ \\
\hline 1 & $\begin{array}{r}? 1 \\
2\end{array}$ & $\begin{array}{r}11 \\
9 \\
42 \\
1\end{array}$ & $\begin{array}{l}1 \\
2\end{array}$ & $\begin{array}{r}1 \\
26\end{array}$ & $? 2$ & $\begin{array}{c}\text { Oral smears } \mathrm{X} \text {-chromatin } \\
\text { positive }\end{array}$ & $\begin{array}{l}Y=19 \text { in length } \\
\text { Random chromosome change }\end{array}$ & $\begin{array}{c}15 \mathrm{~s} \\
3,21 \mathrm{~s}\end{array}$ \\
\hline & 1 & 14 & 13 & $? 1$ & & Oral smears Y32 YY1 & & \\
\hline
\end{tabular}

Iglish Picture Vocabulary Test.

chimerism in Case 1 (see Ford (1969) for definitions of terms 'mosaic' and 'chimera'). If this explanation is correct, the twin with speech deficit might be expected to have $47, \mathrm{XYY}$ neurological tissue whereas his 'normal' sib may have normal or mosaic tissues.

\section{Discussion}

In this small group we found no evidence of association between delay in speech development and 'minor' chromosome variation, but a correlation seems to exist between major sex chromosome aberration and delay in speech development. This is supported by published reports (Fujita et al., 1972; Crandall, Carrel, and Sparkes, 1972) and by a current survey (R. J. Robinson, personal communication, 1973).

Patients in psychiatric and penal institutions have a much higher incidence of sex chromosome disorders than the general or newborn populations (Court Brown, 1967; Anders et al., 1968; Smith and Jacobs, 1970; Lubs and Ruddle, 1970b; Fujita et al., 1972; Crandall et al., 1972; Hamerton et al., 1972). Unlike individuals with autosomal aneuploidy, many patients with sex chromosome trisomy look relatively normal. The difference is thought to be due to the genic inertness which sex chromosomal material displays, in the soma at least, and this in turn seems correlated with their special heterochromatic features. Heterochromatin can be regarded as inactive genetic material. As far as the $\mathrm{X}$ chromosome is concerned, the Lyon hypothesis (Lyon, 1961) is that during early embryogenesis $\mathrm{X}$ chromosomes in excess of one, previously capable of genetic expression, are inactivated to form the facultative heterochromatin (Brown, 1966) visible as the X-chromatin mass (Barr body) in the interphase nucleus. There is considerable evidence for this hypothesis, but some loci on the $\mathrm{X}$ chromosome might escape inactivation. The $\mathrm{Y}$ chromosome also seems to be heterochromatic, but the character of its heterochromatin is different (Polani, 1968) and seems to be constitutive rather than facultative, at least in somatic cells. The greater the number of sex chromosomes, and hence the amount of heterochromatin present in a genome, the more severely an individual is affected or retarded, each $\mathrm{X}$ or $\mathrm{Y}$ added having a cumulative but slightly differing effect on many characteristics, particularly intelligence (Polani, 1967, 1969; Hamerton, 1971; Barlow, 1973). These effects of extra sex chromosomes must either be expressed in the early development of the embryo-in which case their activity might be that of the genes they contain, or else it must be presumed that the heterochromatin has some subtle form of expression when embryogenesis and organogenesis are complete (Polani, 1968, 1969; Hamerton, 1968; Mittwoch, 1967). Both may be true. It seems likely that the greatest effect of heterochromatin is in retarding development (Polani 1967, 1969; Barlow, 1973), possibly due to differences in a number of cell characteristics including their size, organization, and especially growth (Hamerton, 1971; Angell, 1969; Barlow, 1972).

The finding of two mosaic individuals in our small 
sample may be highly significant or purely fortuitous. The population frequency of individuals mosaic for two cell lines is not known. Large-scale surveys of newborn populations based on chromosome studies have, for practical purposes, been limited to a study of two cells per patient. The chances, therefore, of detecting mosaicism are very low. In the three largest published surveys of newborn populations (Lubs and Ruddle, 1970b; Ratcliffe et al., 1970; Hamerton et al., 1972), no mosaics were detected in 9000 males studied. In $\mathbf{X}$-chromatin surveys of newborn males carried out in Edinburgh (Court Brown, 1967), 5 mosaics $46, X Y / 47, X X Y$ were discovered in 13,257 liveborn males, a rate very close to that detected by Fujita et al. (1972) in sex chromatin studies on schoolchildren. In the light of these results, our discovery of two mosaics in 9 patients seems highly significant, but as pointed out above it is possible that one (Case 1) is a blood chimera and not a mosaic. However, the chances of finding one mosaic in the series seems to be less than 1 in 250 . We tried to exclude the effect on speech development of 'global' mental retardation by selecting for normal comprehension of speech with retarded expressive speech levels, and thus we could expect to select against pure line chromosomal abnormalities with mental impairment. The child with a 48,XXYY karyotype illustrates this point as he only just falls within the selection criteria. Available evidence suggests that mosaic individuals with both normal and abnormal cell lines show less severe clinical symptoms than non-mosaic subjects with abnormal karyotype. However, despite their relatively normal IQ distribution, the frequency of sex chromosome mosaic individuals in mental hospitals is similar to that of patients with 47,XXY Klinefelter's syndrome, namely 5 to 6 times higher than that in newborn populations. Polani (1969) has suggested that this may be due to the admixture of different cell lines in the brain upsetting higher functions and social adaptation with subsequent hospitalization.

While considering the significance of our findings, it is perhaps worth pointing out that only one child with 48,XXYY karyotype (Court Brown, 1967) was found in 22,000 male births in the surveys quoted above. Crandall et al. (1972) reported one child with this karyotype among 700 psychiatric referrals; it does seem, therefore, that such children may present either with developmental problems or mental retardation.

It is widely accepted that there is a relation between intelligence and language levels. If the intelligence levels of children with single sex chromosome aneuploidy (e.g. 45,X; 47,XXY) are examined, the general IQ may be close to the normal but the distribution is negatively skewed. However, if the verbal and performance values are compared, it is found that in individuals with sex chromosome monosomy $(45, \mathrm{X})$ the performance IQ is lower than the verbal IQ, whereas in Klinefelter's syndrome $(47, \mathrm{XXY})$ the reverse is true but less consistently so (Money, 1963; Moor, 1967; Polani, 1969). In children with various forms of sex chromosome aneuploidy related to Klinefelter's syndrome, this discrepancy between levels of verbal and performance IQ presents as speech retardation, a finding supported by the work of Crandall et al. (1972) and Fujita et al. (1972) in psychiatric patients. Conversely, we might expect children with the sex chromosome changes responsible for Turner's and some related syndromes to be referred for problems of motor co-ordination.

Many social and environmental factors could affect the age at which all these patients might be recognized as needing help, but it is important that they be referred for remedial help in the first few years of life. The children with more extreme sex chromosome disorders and the associated mental impairment would probably be referred later to special purpose schools.

It is apparent from this and published reports that the retardation of speech development may be a diagnostic criterion for selecting chromosomally anomalous patients in prepubertal populations. If this is so, future experience may show us ways of giving supportive therapy directed not only at their speech defect, but more generally at preventing the development of psychosocial maladjustment. In the cases reported here, expressive language deficit is responding to therapy and we hope that care from infancy may prevent the adaptive crises which could lead to psychiatric referral later in life.

This paper is based on a project carried out by M.G. in part requirement for the $M$.Sc. degree at London University. M.G. thanks the Salford Hospitals Management Committee for granting study leave.

We thank our many colleagues in both Manchester and London for their contributions, and particularly Professor P. E. Polani for comments on the findings, James Thompson for help in language data preparation, and Helen Kingston for co-ordinating the patients; and Mr. Leslie Butler of Queen Elizabeth Hospital for Children, Hackney, for permission to quote his results.

Work done at the Paediatric Research Unit was supported by grants from the Spastics Society, the Department of Health and Social Security, and the Children's Research Fund, Liverpool.

$$
\text { REFERENCE; }
$$

Anders, J. M., Jagiello, G., Polani, P. E., Giannelli, F., Hamerton, J. L., and Leiberman, D. M. (1968). Chromosome findings in chronic psychotic patients. British fournal of Psychiatry, 114, 1167. 
Angell, R. R. (1969). Cytogenetic and genetic studies in Turner's syndrome and allied conditions in man. Ph.D. Thesis. University of London.

Barlow, P. W. (1972). Differential cell division in human $X$ chromosome mosaics. Humangenetik, 14, 122.

Barlow, P. (1973). The influence of inactive chromosomes on human development. Humangenetik, 17, 105.

Brown, S. W. (1966). Heterochromatin. Science, 151, 417.

Caspersson, T., Lomakka, G., and Zech, L. (1971). The 24 fluorescence patterns of the human metaphase chromosomes; distinguishing characters and variability. Hereditas, 67, 89.

Court Brown, W. M. (1967). Human Population Cytogenetics. North-Holland, Amsterdam.

Crandall, B. F., Carrel, R. E., and Sparkes, R. S. (1972). Chromosome findings in $\mathbf{7 0 0}$ children referred to a psychiatric clinic. Fournal of Pediatrics, 80, 62.

Fawcus, B. (1969). Oropharyngeal function in relation to speech. Developmental Medicine and Child Neurology, 11, 556.

Ford, C. E. (1969). Mosaics and chimaeras. British Medical Bulletin, 25, 104.

Fujita, H., Yoshida, Y., Tanigawa, Y., Yamamoto, K., and Sakamoto, Y. (1972). A survey of sex chromosome anomalies among normal children and mental defectives. fapanese Journal of Human Genetics, 16, 198.

Hamerton, J. L. (1968). Significance of sex chromosome derived heterochromatin in mammals. Nature (London), 219, 910.

Hamerton, J. L. (1971). Human Cytogenetics. II. Clinical Cytogenetics. Academic Press, London and New York.

Hamerton, J. L., Ray, M., Abbott, J., Williamson, C., and Ducasse, G. C. (1972). Chromosome studies in a neonatal population. Canadian Medical Association fournal, 106, 776.

Kirk, S. A., McCarthy, J., and Kirk, W. D. (1968). Illinois Test of Psycholinguistic Abilities (Rev. Ed.). University of Illinois, Illinois.

Lubs, H. A., and Ruddle, F. H. (1970a). Applications of quantitative karyotypy to chromosome variation in 4400 consecutive newborns. In Human Population Cytogenetics, p. 119. Ed. by P. A. Jacobs, W. H. Price, and P. Law. The University Press, Edinburgh.

Lubs, H. A., and Ruddle, F. H. (1970b). Chromosomal abnormalities in the human population: estimation of rates based on New Haven newborn study. Science, 169, 495.

Lyon, M. F. (1961). Gene action in the X-chromosome of the mouse (Mus Musculus L.). Nature (London), 190, 372.

Mittwoch, U. (1967). Sex Chromosomes. Academic Press, London and New York.

Money, J. (1963). Cytogenetic and psychosexual incongruities with a note on space-form blindness. American fournal of Psychiatry, 119, 820.

Moor, L. (1967). Niveau intellectual et polygonosomie. Revue de Neuropsychiatrie Infantile, 15, 325.

Polani, P. E. (1967). Chromosome anomalies and the brain. Guy's Hospital Reports, 116, 365.

Polani, P. E. (1968). Chromosomal abnormalities and congenital heart disease. Guy's Hospital Reports, 117, 323.

Polani, P. E. (1969). Abnormal sex chromosomes and mental disorder. Nature (London), 223, 680.

Ratcliffe, S. G., Stewart, A. L., Melville, M. M., and Jacobs, P. A. (1970). Chromosome studies on 3500 newborn male infants. Lancet, 1, 121.

Reynell, J. K. (1969). Test Manual Reynell Developmental Language Scales. (Experimental ed.) National Foundation for Educational Research, London.

Smith, P. G., and Jacobs, P. A. (1970). Incidence studies of constitutional chromosome abnormalities in the post-natal population. In Human Population Cytogenetics, p. 159. Ed. by P. A. Jacobs, W. H. Price, and P. Law. The University Press, Edinburgh.

Correspondence to D. E. Mutton, Paediatric Research Unit, Guy's Hospital Medical School, London SE1 9RT. 